Discussion Paper No. $\quad 565$

\title{
SHOULD THE COINSURANCE RATE BE INCREASED IN THE CASE OF THE COMMON COLD? -AN ANALYSIS BASED ON AN ORIGINAL SURVEY-
}

\author{
Yasushi Ohkusa \\ and \\ Masako li
}

May 2002

The Institute of Social and Economic Research Osaka University

6-1 Mihogaoka, Ibaraki, Osaka 567-0047, Japan 
(forthcoming in Journal of Japanese and International Economics)

\title{
Should the Coinsurance Rate be Increased in the Case of the Common Cold? \\ -An Analysis Based on an Original Survey- *) \\ Yasushi Ohkusa \\ Osaka University \\ and \\ Masako Ii \\ Yokohama National University
}

\begin{abstract}
This article examines the choice of health care in Japan by patients suffering from the common cold. Original data were obtained from a survey conducted by the authors. Empirical results show that the price elasticity of demand for medical services is between 0.23 and 0.36. This estimated price elasticity suggests that if the new medical insurance reform plan were to increase the coinsurance rate by $10 \%$ both for those insured and their and dependants, national medical costs may be reduced by, at most, 43 billion yen (358 million US dollars); correspondingly, this could increase the demand for over-the-counter (OTC) medicine, at most, by 8.8 billion yen (73.3 million US dollars). This result implies that medical services and OTC medications are substitutes. Moreover, a tenfold increase in the provision of information on drugs could reduce national medical costs by 60 billion yen (500 million US dollars) at most, with a corresponding increase in the demand for OTC medications by about 6.9 billion yen (57.5 million U.S. dollars).
\end{abstract}


JEL Classifications: I11,I12, I31, I18

Keywords: minor illnesses, medical service demand, medical insurance system, over-thecounter medication 


\section{Introduction}

Japan's health care system has been relatively successful. Gross health indicators are the best in the world: the infant mortality rate is $0.46 \%$ of live births, and the life expectancy is 75.9 years for males and 81.8 years for females(World Bank, 1998).

There is universal coverage with virtually unlimited access to all health care facilities. As a ratio of national income in Japan, national medical costs were $7.09 \%$ in 1995 . This figure is a little more than half of the same ratio in the United States. However, in 1997 national medical costs exceeded 28 trillion yen (about 230 billion US dollars) and continue to rise by at least one trillion yen per year.

At least three factors account for this expenditure growth. The first factor is the aging population. The Japanese population is aging at a much faster rate than in other industrial nations, and this is expected to contribute to a continued rise in the costs of medical care.

The second factor is the high utilization of hospitals. In Japan there is little functional differentiation between clinics and hospitals, and their boundary is further blurred because a third of the clinics have a small number of beds (the distinction is primarily legal in that facilities with more than 20 beds are designated as hospitals, whereas those having fewer than 20 are called clinics). Neither is there much differentiation between acute and long-term care(Ikegami, 1992). The price charged by all providers (hospitals and clinics) is uniform, assuming that their quality is the same. However, patients are increasingly turning away from clinics in favour of hospitals because of their perceived higher quality. As a result, there are long queues for outpatients' visits and waiting lists for admissions to hospital. This situation is difficult to reverse because 'freedom of choice' is regarded as the cardinal principle in the delivery of health care in Japan.

The third factor is the high per capita costs for medications. Most physicians in clinics do their own dispensing, and hospital-based doctors dispense from the associated institution's pharmacy. The government sets no limits on the quantity of medications dispensed. 
Market prices are surveyed periodically by the government and reimbursement prices are accordingly adjusted. However, providers continue to make profits because competition leads to continual price-cutting. They maintain that they need this margin to offset the relatively low reimbursement rates for the medical procedures they provide. Therefore, doctors have an incentive to over-prescribe. Patients' medical insurance covers medication costs, giving them a price incentive to favour prescribed products.

The health care reform plan proposes to increase the coinsurance rate for relatively minor illnesses, as well as for prescribed medications for these minor illnesses. Minor illnesses are illnesses such as the common cold and diarrhoea, which are curable by standard treatment and at reasonable cost. As there are a few options besides medical services provided by a hospital or a clinic, the anticipated effect of an increase in the coinsurance rate on national medical costs is not clear. If patients are not sensitive to a price change, an increase in the coinsurance rate may not have an appreciable effect on national costs. On the other hand, if patients are sensitive to a price increase, they may choose other options and decide to seek medical services less frequently. An increase in the coinsurance rate will then decrease the national medical costs.

In this paper we assume that when suffering from minor illnesses a patient has three options: he or she can consult a doctor, can purchase OTC medications, or do nothing. The price sensitivity, therefore, may be relatively high, but this has to be tested empirically 1).

The demand for OTC medications has been analysed since the 1960s(Greenlick and Darsky, 1968). However, it was not until the 1990s that researchers emphasized the savings that governments may make by switching to OTC drugs(Johnson, 1991; McNamee, 1994). In the late 1980s the British government supported the OTC medicine market by reclassifying certain prescription medicines to allow OTC sales in pharmacies. Eleven medicines were reclassified between 1983 and 1992, and from 1992 to early 1996, 40 more medicines were reclassified(Blenkinsopp and Bradley, 1996). 
McNamee(1994) pointed out that in France, if annual OTC sales were to increase by $10 \%$, the saving would be about FF 3.4 billion. In the Netherlands, if 10-15 million visits to the doctor could be avoided, the savings to the state from self-medication would amount to DG 450-750 million. However, these figures are estimates by medical practitioners and pharmacists, and are not based on proper economic analysis.

In the United States, where extensive research on health economics is undertaken, only a few studies focus on demand for medical services related to minor illnesses, or on the substitution between prescribed and OTC medications (Stuart and Grana, 1995; Fillenbaum et al., 1993). Of these few studies, particular attention is paid to the research of Leibowitz(1989) because of its originality and, most of all, its research design. The research was part of the study referred to as the Health Insurance Experiment (HIE) that Newhouse(1993) and others at the RAND institute initiated in 1971, lasting for about 10 years. HIE was a longitudinal study that experimentally altered the medical care cost-sharing faced by families. Between November 1974 and February 1977 HIE assigned families to insurance plans that differed in the amount of cost-sharing. According to this study, under a free plan (defined as no out-of-pocket cost to the family), compared to a $95 \%$ coinsurance plan (families paid $95 \%$ of their medical expenses), the demand for medical services increased by about 20\%. The spending on medical services under the free plan was $50 \%$ more than that of the $95 \%$ coinsurance plan. This means the price elasticity of medical service was, on average, 0.21 .

Using the HIE, Leibowitz(1989) focused on minor illnesses and analysed the substitution between prescribed and OTC medications. Her empirical results did not support the expectation that people assigned less generous insurance for prescription drugs substitute OTC for prescriptions. Although the price elasticity was not accounted for in either study, Newhouse(1993) indicated that, in the case of influenza, the price elasticity was around unity. This suggests that for minor illnesses, the demand for medical services is relatively sensitive to price. 
In Japan there are only a few studies that estimate the demand for medical services. Among these studies, Yamada(1997) used hospital-based data to estimate the demand for medical services. Without the use of a household-based survey, he was not able to analyse patients' preferences, decisions and behaviour regarding medical services.

Ii and Ohkusa(1998) were the first to attempt an estimation of the demand for medical services related to minor illnesses. They modelled explicitly the incidence of minor illnesses and, using micro household data, measured the price elasticity of the demand for medical care for minor illnesses in Japan. Their data, from the Comprehensive Survey of Living Conditions(CSLC), were not experimentally or extensively collected like the data in the HIE. However, the sample size in the CSLC - about 600,000 - is much larger compared to that of the HIE, which was about 2000. CSLC includes household and individual characteristics such as gender, age, income and assets, and detailed health information. Their results show that the price elasticity for medical services was 0.208 , which is comparable to that for the United States, and that medical services and OTC medications are substitutes.

Using patients' health information from the CSLC to define minor illnesses, Ii and Ohkusa(2002) estimated price elasticities for various minor illnesses. They found that in the case of minor illnesses, the price elasticities for medical services were between 0.144 and 0.149 . The data set also included detailed information on 43 subjective symptoms. The authors estimated price elasticities separately for medical services demanded for these 43 symptoms and found that, for almost half of the symptoms, the price elasticities estimated were less than unity.

This paper, using original data from a survey conducted by the authors, examines the choice of health care in Japan for patients suffering from the common cold. Empirical results show that the price elasticity for medical services is between 0.23 and 0.36 .

Section 2 of the paper presents the major hypotheses of the study, section 3 describes the data, the empirical model is explained in Section 4 and the empirical results are given in Section 5. Concluding remarks are then given. 


\section{Hypotheses}

Risk aversion and uncertainty about future health events create a demand for medical insurance. However, once insurance is in place, moral hazard leads to over-utilization of medical care. This phenomenon may be more serious in the case of relatively minor illnesses. As in the analysis of the optimal commodity tax, there is no reason for rates of insurance to be the same for different types of health care. In this section, the effects on national medical costs and patients' consumer surplus are analysed under an assumed scenario where the new medical insurance reforms exclude minor illnesses from insurance coverage.

Under the universal medical insurance plan, there is a gap between the price a patient faces and its social cost. Figure 1 shows the market for medical services. The vertical axis shows the social costs of medical services and the horizontal axis shows the corresponding quantities of medical services. In our model, quantity is measured by the proportion of patients who visited doctors out of the total number of patients. The supply curve (SS) is horizontal in the short run. This reflects the fact that in Japan doctors cannot refuse treatment and cannot increase prices in times of high demand. Queuing is the rationing device used to limit demand. The value of waiting time is part of the implicit price.

Suppose $D D$ refers to the demand for patients without medical insurance and $D^{\prime} D^{\prime}$ is for patients with medical insurance. Suppose further that the current price level is given by $A O$ so that the current quantity consumed in the market by patients without medical insurance is given by $Q O$. Hence, total expenditure on the commodity is given by the area of the rectangle $A O Q H$. However, if the market demand curve is actually equal to $D D$, then some consumers would be willing to pay more for some units of the commodity than the market price $A O$. The total amount that consumers would be willing to pay is equal to the rectangle $A O Q H$ plus the triangle $G H A$, which is the consumer surplus.

Under a medical insurance plan, the patient is on the demand curve $D^{\prime} D^{\prime}$ and increases 
his demand from $Q O$ to $Q^{\prime} O$. Since a coinsurance costs $B O$, he pays $B O Q^{\prime} F$ and the government pays $A B F E$. The consumer surplus increases by $A B F H$ and the national medical costs increase by $H Q Q^{\prime} E$. If an increase in consumer surplus $(A B F H)$ is greater than the increase in national medical costs $\left(H Q Q^{\prime} E\right)$, then medical insurance is beneficial to consumers. In order to measure the effect of a rise in the coinsurance rate on national medical costs, a demand function for medical services needs to be estimated.

The demand for medical services by a patient $i$ suffering from a minor illness at period $t$ depends on the price of the medical service or coinsurance, $p_{i, t}^{M}$, the price of a close substitute such as OTC medications $p_{t}^{O}$, income $I_{i, t}$, the opportunity cost of visiting a doctor $C_{i, t}$, and other variables that affect the demand for medical services $Z_{i, t}$. Therefore, the demand for medical services is expressed as $d\left(p_{i, t}^{M}, p_{t}^{O}, I_{i, t}, C_{i, t}, Z_{i, t}\right)$. The variable $Z_{i, t}$ includes health capital, employment status, and attitudes toward medical services.

In this paper, the hypotheses to be tested are that: 1) medical services are normal goods in an economic sense, and 2) medical services are substitutes for OTC medication. Using the above notations, these hypotheses can be expressed as $\frac{\partial d}{\partial p_{i, t}^{M}}<0, \frac{\partial d}{\partial p_{t}^{O}}>0, \frac{\partial d}{\partial I_{i, t}}>0, \frac{\partial d}{\partial C_{i, t}}<0$,

and $\frac{\partial d}{\partial Z_{i, t}}<0$. That is, an increase in coinsurance decreases the demand for medical care, an increase in the price of OTC medications increases the demand for medical care, an increase in income level increases the demand for medical care, an increase in the time cost decreases the demand for medical care, and, finally, an increase in health capital decreases the demand for medical care. When relatively healthy people suffer from an illness, they are more likely to recover sooner than do other sufferers. Therefore, the marginal cost of receiving medical services is considered to be low.

\section{Data}

The data for this research were obtained from a survey conducted from November 1, 1997, to January 20, 1998, in Kanto (Tokyo, Kanagawa, Saitama, and Chiba) and Kansai (Osaka, 
Kyoto, Nara, and Hyogo) areas. The questionnaire asked about household and individual characteristics, as well as illness histories, treatments, and progress. Of the total 600 questionnaires distributed, 548 were completed and returned ${ }^{2)}$.

The most important finding from the survey was the variation in the coinsurance rates. Under the Japanese health insurance system, except for the $0.6 \%$ of the population receiving public health care assistance, through legislation all Japanese must be covered by National Health Insurance or Employees' Insurance plans. For self-employed persons, pensioners and their dependants (National Health Insurance), the coinsurance rate is set by the government at 30\%. For employees (Employees' Insurance), the coinsurance rate is set at $20 \%$ of the medical costs, and at 30\% for their dependants. However, Table 1 shows that coinsurance rates vary from zero to $30 \%$. At least $9 \%$ of employees and $19.4 \%$ of their dependants were receiving medical services beyond government provision.

The questionnaire identified patients suffering from a common cold, stiff shoulders, and stomach-ache. As a sufficient sample size was obtained for those suffering only from a common cold, the analysis was restricted to patients suffering from this complaint. The analysis focuses on those between the ages of 22 and 59 years. This age group faces higher opportunity costs and is, therefore, an appropriate sample for analysing the substitutability between the demand for medical services and the demand for OTC medications. Our sample areas, the Kanto and Kansai areas, enjoy a higher enrolment rate in college and university than any other area in Japan. Therefore, we focus on those older than 22 years of age. Moreover, for those older than 60 years, special medical care benefits are available through the Medical Services Act for the Aged. For those younger than six years, each local government provides an array of health services.

Table 2 shows the sample statistics. The sample size is 225. Among the patients who suffered from a common cold, $42 \%$ sought medical services in hospitals, $41 \%$ purchased OTC medications and $17 \%$ did not seek medical attention.

OTC prices were collected for this survey, but the sample size was too small to be 
analysed. Instead, the prices of one popular brand of OTC medication are used because the authors were able to obtain regional sale prices on this particular brand ${ }^{3)}$.

Table 2 reveals the following characteristics: $28.9 \%$ of the patients are in their thirties, $24 \%$ are in their forties, and $25 \%$ in their fifties. Of the total 225 patients, $60 \%$ are female, $24 \%$ are college graduates, $11 \%$ are junior college graduates, $5.3 \%$ finished technological college, and $9.3 \%$ finished vocational school. More than $70 \%$ of the patients are in paid employment and 16\% are self-employed. The average annual income from labor and other sources is 0.27 million yen and 1.71 million yen respectively. The patients suffered from a common cold for an average of 5.78 days and as a consequence remained in bed for an average of 0.37 days. The average body temperature of the respondents is 36.9 degrees. On average, patients suffer from a cold 3.56 times a year. Among the patients, $27 \%$ exercise regularly, $27 \%$ smoke regularly, and $10.2 \%$ drink heavily. Knowledge of medications is modelled as a dummy variable that takes the value of 1 if patients know about 'H2 blockers' or if they answer that they have good knowledge of medications, and zero otherwise.

Table 3 shows the cross-tabulations between coinsurance rates and treatments (medical services and OTC medications). According to this table, when the coinsurance rate is equal to or less than $20 \%, 44.2 \%$ seek medical services while $43.3 \%$ purchase OTC medications. When the coinsurance rate is $30 \%$, both demands for medical services and OTC medications decrease to $41 \%$ and $40.3 \%$, respectively. However, when the coinsurance rate is $30 \%$ compared to $20 \%$ or less, those in their fifties increase the demand for OTC medications. In the next section, we analyse how the change in coinsurance rate affects the demand for medical services and OTC after controlling various factors such as age or job status.

\section{Estimation Models}

The dependent variable takes three values: $T_{i, t}=1$ if a patient demands medical services, $T_{i, t}=2$ if a patient demands OTC medications, and $T_{i, t}=0$ in other cases. The inde- 
pendent variables are age $A_{i, t}$, gender $\left(G_{i, t}=1\right.$ if female, $G_{i, t}=0$ if male), his or her own labor income $I_{i, t}$, per capita household income net of own labor income $\check{I}_{i, t}$, education $E_{i, t}$, a health capital dummy $H_{i, t}$, a job status dummy $\left(W_{i, t}=1\right.$ if a patient works and $W_{i, t}=0$ if otherwise), a self-employed dummy $J_{i, t}^{S}$, seriousness of illness dummy $S_{i, t}$, a knowledge of medications dummy $D_{i, t}$, price of OTC medications in the region, $P_{i, t}^{O T C}$, and the coinsurance rate $\left.P_{i, t}^{M} \cdot 4\right)$

We have the following empirical specification:

$$
\begin{aligned}
T_{i, t}^{j *}= & 3 D \quad \alpha_{0}^{j}+\alpha_{A}^{j} A_{i, t}+\alpha_{G}^{j} G_{i, t}+\alpha_{I}^{j} \log I_{i, t}+\alpha_{\check{I}}^{j} \log \check{I}_{i, t}+\alpha_{E}^{j} E_{i, t}+\alpha_{H}^{j} H_{i, t} \\
& +\quad \alpha_{J}^{j} J_{i, t}+\alpha_{J^{S}}^{j} J_{i, t}^{S}+\alpha_{S}^{j} S_{i, t}+\alpha_{D}^{j} D_{i, t}+\alpha_{p^{O T C}}^{j} P_{i, t}^{O T C}+\alpha_{p^{M}}^{j} P_{i, t}^{M}+\varepsilon_{i, t}^{j} \quad(j=0,1,2) \\
T_{i, t}= & \begin{cases}1 & \text { if } T_{i, t}^{1 *}>T_{i, t}^{2 *} \text { and } T_{i, t}^{1 *}>T_{i, t}^{0 *} \\
2 & \text { if } T_{i, t}^{1 *}<T_{i, t}^{2 *} \text { and } T_{i, t}^{2 *}>T_{i, t}^{0 *} \\
0 & \text { otherwise }\end{cases}
\end{aligned}
$$

The three choices are mutually exclusive as these choices are the last actions that patients took $^{5)}$. For estimation, therefore, the multinomial probit method is used(Daganzo, 1979) 6). Because the probability of choosing $j$ adds up to 1 , we can estimate the differences in probability. Here, we set $j=0$, the choice of 'do nothing', as the basis for comparison. The error term, $\varepsilon_{i, t}^{j}(j=0,1,2)$, is a random variable and $\Omega$ follows a three-dimensional normal distribution. As the error terms in the estimation are also redefined by the difference from $\varepsilon_{i, t}^{0}$ and $\varepsilon_{i, t}^{j}(j=1,2)$, and the $(1,1)$ element of the variance-covariance matrix is normalized to be 1 , the matrix should be

$$
\left[\begin{array}{lll}
-1 & 1 & 0 \\
-1 & 0 & 1
\end{array}\right] \Omega\left[\begin{array}{lll}
-1 & 1 & 0 \\
-1 & 0 & 1
\end{array}\right]^{\prime}\left[\begin{array}{ll}
1 & \rho \\
\rho & \sigma
\end{array}\right] .
$$

The estimation procedure is the BHHH method with a grid search over $\rho$ and $\sigma$. This procedure is accurate, as Keane(1992) has shown.

The bootstrapping technique is used to obtain a description of the sampling properties of empirical estimator using the sample data, rather than a theoretical result such as an asymptotic theorem (Efron(1979), Shao and Tu(1995), Greene(1997)). In our model, the 
small sample relative to the complex model makes any asymptotic theorem inappropriate. Bootstrapping is performed as below. Suppose that $\hat{\theta}_{n}$ is an estimate of a parameter vector based on a sample $X$ with $n$ sample. An approximation to the statistical properties of $\hat{\theta}_{n}$ can be obtained by studying a sample of the bootstrap estimator $\hat{\theta}(b)_{m}, b=1, \cdots, B$, obtained by sampling $m$ observations, with replacement, from $X$ and recomputing $\hat{\theta}$ with each sample. This is done a total of $B$ times and the desired sampling characteristics is computed from $\hat{\Theta}=\left[\hat{\theta}(1)_{m}, \hat{\theta}(2)_{m}, \cdots, \hat{\theta}(B)_{m}\right]$. The bootstrapped $\alpha \%$ nonparametric confident interval is $\left[\hat{\theta}(\alpha / 2 * B)_{m}^{s}, \hat{\theta}((1-\alpha / 2) * B)_{m}^{s}\right]$ where $\hat{\theta}(b)_{m}^{s}$ is sorted $\hat{\theta}(b)_{m}$ by the number of it. In our case, $m=n$ and $B=1000$.

\section{Estimation Results}

Tables 4 and 5 show the marginal effects of demand for medical services and OTC medications when patients suffer from a common cold. These effects show how a one-unit change in the explanatory variables changes the probability of choosing medical services or OTC medications. For example, for those with college and university degrees the probability of choosing medical services and OTC medications is $12 \%$ lower and $16.1 \%$ higher, respectively, than for those with lower educational attainment.

Table 4 shows that the coefficient for the coinsurance rate is -0.231 . This implies that the demand curve is downward sloping, and a one percent increase in the coinsurance rate reduces medical demand by 0.23 percentage points. Increasing the coinsurance rate from the current average rate of $27.5 \%$ to $100 \%$ would decrease the demand for medical services by 17 percentage points to $25 \%$ of current levels. The government saving on its spending on medical costs would be $40 \%$.

Table 5 shows that the coefficient for the coinsurance rate is 0.395 . Increasing the coinsurance rate from the current average rate of $27.5 \%$ to $100 \%$ increases the demand for OTC medications by 30 percentage points to $71 \%$. These results are comparable to those 
in Ii and Ohkusa(1998, 2002), who showed that the price elasticity for medical services is 0.208 (Ii and Ohkusa(1998)), and price elasticities are 0.55 for fever, 0.28 for sore throat, and 0.27 for stomach-ache (Ii and Ohkusa(2002)).

The cross-price elasticity, measuring the effect of the coinsurance rate on the demand for OTC medications, is much higher than that in Ii and Ohkusa(2002). Table 5 shows that a one per cent increase in the coinsurance rate increases the demand by 40 percentage points, which is almost five times higher than the 8.5 percentage points in Ii and Ohkusa(2002). The advantage of this paper over other studies is that it uses more detailed information on OTC medication prices as well as on individual characteristics.

The effects of an increase in the OTC price on OTC medications and medical service demand are as follows. The own-price elasticity is -0.03 ; the effect on OTC medication demand is negative and significant but very small. This means that a $10 \%$ increase in the prices of OTC medications decreases the demand for OTC medications by only $0.3 \%$. Therefore, OTC sales would be increased by $9.7 \%$ by value. OTC demand is very inelastic. On the other hand, the effect of an increase in OTC prices on medical service demand is positive, but not significant.

Some caution is needed with the above interpretation. The OTC price data were collected from pharmacies in the regions where the survey was conducted. These prices may reflect competition among the pharmacies rather than the OTC prices that consumers actually face. Moreover, OTC prices are those for one particular brand, and do not represent the whole OTC market. Particular care is needed in interpreting these results regarding the effects of OTC prices on medical service demand and the demand for OTC medications.

As for health capital (exercise, drinking, and smoking habits), patients who exercise regularly have a four percentage points greater demand for medical services, a three percentage points greater demand for OTC medications, and a seven percentage points less tendency to do nothing compared to those who are not regular exercisers. Smokers have a 14 percentage points lower medical demand, a six percentage points higher demand for OTC 
medications, and an eight percentage points greater tendency to do nothing compared to non-smokers. Heavy alcohol drinkers have a 10 percentage points lower demand for OTC medications and a nine percentage points greater tendency to do nothing compared to moderate or non-alcohol drinkers. These results imply that people who do not exercise regularly or who have vices are more likely to choose to do nothing, given a common cold.

For seriousness of illnesses, if patients stay in bed for one day, the demand for medical services increases by 10 percentage points and the demand for OTC medications decreases by 10 percentage points. If patients suffer from a one degree increase in body temperature, their demand for medical services increases by 18 percentage points and their OTC medication demand decreases by seven percentage points. When the condition of illness worsens, the demand for medical services increases and the demand for OTC medication decreases.

Compared to patients in their twenties, the demand for medical services by those in their thirties increases by nine percentage points, increases by six percentage points when they reach their forties, and decreases by six percentage points when they reach their fifties. On the other hand, compared to patients in their twenties, the demand for OTC medications by those in their thirties decreases by two percentage points, decreases by three percentage points when they reach their forties, and increases by four percentage points when they reach their fifties. These results may reflect a social responsibility faced by people in their fifties that is not captured by the variables in the model such as work status or income.

Among different education levels, patients with a vocational school degree have the highest demand for medical services, followed by high school graduates, junior college and technological college graduates. College and university graduates have the lowest demand for medical services. On the other hand, college and university graduates have the highest demand for OTC medications followed by junior college and technological college, high school and vocational school graduates. Overall, patients with higher education demand more OTC medications and less medical services. Similar results have been found 
from studies in the United States (Fillenbaum et al.(1993), Leibowitz(1989), Stuart and Grana(1995)).

Employed patients have a two percentage points lower demand for medical services, and a two percentage points higher demand for OTC medications compared to those without employment. This implies that employed patients have a higher time cost. However, a one per cent increase in labor income increases demand for medical services by two percentage points, decreases the demand for OTC medications by two percentage points and decreases the tendency to do nothing by 0.8 of a percentage point. An increase in other income has a similar effect on demands. In the case of the common cold, the income effect seems to be larger than the price effect.

Patients who know of $\mathrm{H}_{2}$ blockers, or who answered that they have a good knowledge of medications, have an 11 percentage points lower demand for medical services, a nine percentage points higher demand for OTC medications, and a two percentage points higher tendency to do nothing compared to those without knowledge of medications.

If the new medical insurance reform plan were to increase the coinsurance rate by $10 \%$ for both those who are insured and their dependants - that is, to $30 \%$ for the insured and $40 \%$ for dependants - the price elasticity for medical service demand suggests that medical services demanded would decrease by 2.3 percentage points, to a level of $39.7 \%$. The Nomura Research Institute(1998) estimated that in 1995 national medical costs of treating the common cold were 500 billion yen (4.16 billion US dollars). Using this estimate of the national medical costs, a 2.3 percentage points decrease in demand would help the Japanese government save 27 billion yen (255 million US dollars) on medical costs.

The cross-price elasticity of OTC medication suggests that the demand for OTC medications would increase by about four percentage points to $45 \%$. Given that the OTC market for common cold medications is estimated at around 90 billion yen (750 million US dollars), a $10 \%$ increase in the coinsurance rate increases the demand for OTC medications by 8.8 billion yen (73.3 million US dollars). These results imply that medical services and OTC 
medications are substitutes.

Knowledge of medications can help reduce the national expenditure on medical care. In the present survey, $3.5 \%$ of the respondents answered that they have a good knowledge of medications. Let us suppose that $35 \%$ of the population becomes knowledgeable about medications. For example, a pharmacist might provide more information at the pharmacy, public health education may be provided at schools and in the community, and advertisements may be provided by pharmaceutical companies. Then the resulting demand for medical service would decrease by $3.5 \%$ and reduce national medical expenditure by 41.2 billion yen (343 million US dollars). Correspondingly, the demand for OTC medications would increase by $2.8 \%$ and about 6.2 billion yen (51 million US dollars).

\section{Estimation Results Without Using OTC Prices}

The previous section discussed some problems in collecting data on OTC prices. Therefore, in this section, equation (1) is re-estimated without using OTC prices.

We have the following empirical specification:

$$
\begin{aligned}
& T_{i, t}^{j *}= \alpha_{0}^{j}+\alpha_{A}^{j} A_{i, t}+\alpha_{G}^{j} G_{i, t}+\alpha_{I}^{j} \log I_{i, t}+\alpha_{\check{I}}^{j} \log \check{I}_{i, t}+\alpha_{E}^{j} E_{i, t}+\alpha_{H}^{j} H_{i, t} \\
&+ \alpha_{J}^{j} J_{i, t}+\alpha_{J^{S}}^{j} J_{i, t}^{S}+\alpha_{S}^{j} S_{i, t}+\alpha_{D}^{j} D_{i, t}+\alpha_{p^{M}}^{j} P_{i, t}^{M}+\varepsilon_{i, t}^{j}(j=0,1,2) \\
& T_{i, t} \quad \begin{cases}1 & \text { if } T_{i, t}^{1 *}>T_{i, t}^{2 *} \text { and } T_{i, t}^{1 *}>T_{i, t}^{0 *} \\
2 & \text { if } T_{i, t}^{1 *}<T_{i, t}^{2 *} \operatorname{and}_{i, t}^{2 *}>T_{i, t}^{0 *} \\
0 & \text { otherwise }\end{cases}
\end{aligned}
$$

Table 6 shows that the coefficient for the coinsurance rate is -0.361 . Compared to patients without medical insurance (i.e. a 100\% coinsurance rate), those with a zero coinsurance rate (free out-of-pocket cost) have a 36 percentage point higher demand for medical services, a 29 percentage point lower demand for OTC medications, and a 13 percentage point higher tendency to do nothing. If medical insurance could exclude the common cold from the insurance coverage, then increasing the coinsurance rate from the current average rate of 
$27.5 \%$ to $100 \%$ would decrease the demand for medical services by 29 percentage points to $13 \%$. Therefore, the government would save spending on medical costs of $70 \%$. Table 7 shows that, in the same situation, the demand for OTC medications increases by about 31 percentage points, to $72 \%$.

The price elasticity of 0.36 is slightly larger in this section, where the estimation results were obtained without OTC prices, compared to the price elasticity of 0.23 estimated in the previous section with OTC prices included. Patients who do not exercise and have smoking and heavy drinking habits have less demand for both medical services and OTC medications, and are more likely to 'do nothing'. This tendency is more distinct in these results without the OTC prices. Knowledge on drugs has a stronger effect - lowering the demand for medical services and raising the demand for OTC - than in the previous section. As in the previous section, a tenfold increase in knowledge about medications decreases the demand for medical services by five per cent, reduces the national medical costs by 60 billion yen (500 million US dollars) and increases the demand for OTC medications by $3.1 \%$, corresponding to about 6.9 billion yen (57.5 million US dollars).

If the new medical insurance reform plan were to increase the coinsurance rate by $10 \%$ for both the insured and dependants (i.e., 30\% for the insured and $40 \%$ for dependants), the price elasticity of demand for medical services suggests that the demand for medical services would be decreased by 3.6 percentage points to $38.4 \%$. Using the national medical costs estimated by the Nomura Research Institute(1998), a 3.6\% decrease in demand for medical services would save the Japanese government 43 billion yen (358 million US dollars) in national medical costs. The cross-price elasticity of OTC medication suggests that the demand for OTC medications would increase by about three percentage points. A $10 \%$ increase in the coinsurance rate increases the demand for OTC medications by 6.6 billion yen (55 million US dollars). To summarize, the medical insurance reform plan does have an effect on medical services, but less so on the demand for OTC medications, possibly because of measurement error in the prices for OTC medications affecting the estimated 
results. Provision of information on medications has a stronger and greater effect. For example, providing a tenfold increase in information could reduce national medical costs by 60 billion yen (500 million US dollars), whereas a 10\% increase in the coinsurance rate could reduce national medical costs, at most, by 43 billion yen (358 million US dollars). However, by providing a tenfold increase in information, the demand for OTC medications could also increase by more than six billion yen (50 million US dollars).

\section{Concluding Remarks}

Using original survey data, this article examines the choice of health care in Japan for patients suffering from the common cold. Empirical results show that the price elasticity for the medical service is between 0.23 and 0.36 . These estimates are slightly higher than the estimates obtained by using Comprehensive Survey of Living Conditions but are comparable. The results suggest that for minor illnesses price elasticities are in the range 0.2 to 0.4 .

The price elasticities estimated here suggest that if a new medical insurance reform plan were to increase the coinsurance rate by $10 \%$ both for insured and dependants, national medical costs may be reduced, at most, by 43 billion yen (358 million US dollars) and the demand for OTC medications would increase, at most, by 8.8 billion yen (73.3 million US dollars). This cost containment is attained by an increase of the coinsurance rate for only

the common cold. The Nomura Research Institute(1998) estimated that in 1995 national medical costs for the common cold were 500 billion yen (4.16 billion US dollars), and for all minor ailments were 3.3 trillion yen (27.5 billion US dollars), which is about $13.5 \%$ of total national medical costs. The cost containment provided by an increase in the coinsurance rate for all minor ailments would be significant ${ }^{7}$.

Providing information on medications has a greater effect on reducing national medical costs. For example, by providing a tenfold increase in information on medications, national 
medical costs could be reduced by 60 billion yen (500 million US dollars).

These results were obtained using a longitudinal household survey that included medical information as well as detailed household and individual characteristics. However, the survey asked only the final choice that patients made. There is some possibility of underestimating the demand for OTC medication.

For future research, a survey format should take into account the patients' decisionmaking process. This makes it possible to investigate price elasticity of the OTC medication and cross-price elasticity between medical services and OTC medications will be investigated, and the estimation method improved. Furthermore, research on other minor illnesses such as stomach-ache, stiff shoulder, and minor optical and ear-related illnesses should also be undertaken. 


\section{Footnote}

*) This research benefited from a research meeting 'Research on Minor Illnesses and SelfMedication' held in cooperation with the Taisho Pharmaceutical Co. We would like to acknowledge the comments of participants of the meeting, particularly Masahiro Toriyama and Maki Yoshida of the Nomura Research Institute. The views expressed herein are the authors' own and do not reflect those of their institutional affiliations. We are grateful to an editor and grateful to two anonymous referees for helpful suggestions that have improved the paper. We would also like to acknowledge the assistance provided by Kazuko Matsumoto.

1) Surprisingly, there is no documentation that describes the national medical costs of relatively minor illnesses. One exception is a report on the medical costs for a common cold, with estimates made by the Nomura Research Institute(1998). According to their estimate, in 1995, 500 billion yen were spent on treating the common cold. No estimates are available for other minor illnesses because nationwide surveys are undertaken only on particular days. For example, the Ministry of Health and Welfare conducts a patient survey on the particular day of every year, and a hospital and clinic survey on the particular month of every year. These surveys, conducted in summer or autumn, do not provide a reliable estimate of medical costs or resources used, for example, for the common cold or influenza. An approximate estimate shows that about half of the total medical costs are on outpatients. Of these costs no information is given on the shares of the cost for minor illnesses or for chronic diseases, including geriatric diseases. There is a need for estimates of the medical costs of minor illnesses, which may be provided in future research.

2) All households are paid to participate in the various surveys. These data might 
contain some bias even after carefully designed stratified sampling. However, as independent variables such as age, income, education level, and job status are controlled in the estimations, most biases should be eliminated. As no other surveys on minor ailments comparable to ours are available, we cannot infer the nature of possible biases. Of the surveys on minor ailments, we claim that ours is the most reliable in terms of sample design.

3) The cooperation of the Taisho Pharmaceutical Co. is greatly appreciated.

4) The coinsurance rate captures not only differences between National Health Insurance and Employees' Insurance, as shown in Table 1. It also captures differences in many other factors, such as age, gender, employment status, and income. After controlling such observable variables, there does not seem to be heterogeneity between the National Health Insurance and Employees' Insurance. Moreover, the coinsurance rate is exogenous in this model as it is determined at the time of job hunting, marriage or birth.

5) Of course this does not mean that the patients' actual decisions are mutually exclusive. Some patients see doctors only after conditions do not improve by simply taking OTC medication, while others see doctors immediately. In our analysis we consider both cases as choosing medical services. One reason for making this assumption is that our main interests in this paper are to measure how patients respond to a change in the price of medical services and to measure its effect on national medical costs. Since seeking a professional medical service is usually a final decision, our assumption on exclusiveness is not, we believe, a very strong one. Of course there is some possibility of bias due to this assumption of mutual exclusiveness which may affect the price elasticity of demand for medical services, but the bias will not be large. Although our questionnaire asked only about the final choice that patients made, ideally 
the questionnaire format and analysis should consider the patients' decision-making process.

6) Although multinomial logit models are easier to estimate than multinomial probit models, the odds ratio needs to be independent of the alternatives in multinomial logit models. The Hausman-McFadden(1984) test suggests that if a subset of the choice set is truly irrelevant, omitting the choice set in our model $T_{i, t}=3$ will not systematically affect the parameter estimates. The Hausman-McFadden test statistic was 42.1 (40.8). The estimation results without using the OTC prices are in parentheses. With 23(22) degrees of freedom, the chi-squared test rejects the null hypothesis of independence with a $99 \%$ probability. Therefore, we are not able to use the multinomial logit model.

7) Indirect effects are also expected with an increase of the coinsurance rate for such minor ailments as the common cold, as it might relieve congestion in the big hospitals and reduce the waiting times of more seriously ill patients. 


\section{References}

[1] Blenkinsopps, A. and C. Bradley(1996), "Patients, Society, and the Increase in Self Medication," British Medical Journal, 312(7031), pp.629-32.

[2] Daganzo, C.(1979), Multinomial Probit: The Theory and its Application to Demand Forecasting, Academic Press.

[3] Efron, B.(1979), "Bootstrapping Methods: Another Look at the Jacknife," Annals of Statistics 7, pp.1-26.

[4] Fillenbaum, G., J. T. Hanlon, E. H. Corder, T. Ziqubu-Page, W. E. Wall, Jr. and D. Brock (1993), "Prescription and Nonprescription Drug Use among Black and White Community Residing Elderly," American Journal of Public Health, 83, pp.1577-1582.

[5] Greene, W. H. (1997), Econometric Analysis, Prentice Hall.

[6] Greenlick, M. and B. Darsky (1968), "A Comparison of General Drug Utilization in a Metropolitan Community with Utilization under a Drug Prepayment Plan," American Journal of Public Health, 58(11), pp.2121-2136.

[7] Hausman, J. and D. McFadden (1984), "Specification Tests for the Multinomial Logit Model," Econometrica, 52, pp.1219-40.

[8] Ii, M. and Y. Ohkusa (1998), "Is There Any Substitution Between Medical Services and Over-the-Counter Medications?" Presented at the 1998 Japanese Economic Association at Ritsumeikan University.

[9] Ii, M. and Y. Ohkusa (2002),"Price Sensitivity of the Demand for Medical Services for Minor Ailments: Econometric Estimates Using Information on Illnesses and Symptoms," Japanese Economic Review, forthcoming. 
[10] Ikegami, N. (1992), "The Economics of Health Care in Japan," Science, 258, pp.614618.

[11] Johnson, L. (1991), "The Demand for OTC Medicines: Some Australian Evidence," Asia-Pacific Journal of Public Health, 5(3), pp.228-35.

[12] Keane, M. (1992), "A Note on Identification in the Multinomial Probit Model," Journal of Business and Economic Statistics, 10, pp.193-200.

[13] Leibowitz, A., W. Manning and J. Newhouse (1985), "The Demand for Prescription Drugs as a Function of Cost-Sharing," Social Sciences and Medicine, 21(19), pp.10631069.

[14] Leibowitz, A. (1989), "Substitution Between Prescribed and Over-the-Counter Medications," Medical Care, 27, pp.85-94.

[15] McNamee, D. (1994), "Over-the-Counter over Europe," Lancet, 343(4), p.1629.

[16] Newhouse, J. (1993), Free For All, Harvard University Press.

[17] Nomura Research Institute(1998), "Research on Self-Medication" (unpublished).

[18] Shao, J and D. Tu (1995), The Jacknife and Bootstrap, Springer.

[19] Stuart, B. and J. Grana (1995), "Are Prescribed and Over-the-Counter Medicines Economic Substitutes? A Study of the Effect of Health Insurance on Medicine Choices by the Elderly," Medical Care, 33, pp.487-501.

[20] Yamada, T.(1997), "On the Demand for Medical Services"(in Japanese), Journal of Health Care and Society 7,pp.99-112.

[21] World Bank (1998), World Development Report, Oxford University Press. 


\section{Table 1: Distribution of Coinsurance Rates for Employees' Insurance}

\begin{tabular}{lll}
\hline Coinsurance Rate (\%) & Insured & Dependent \\
\hline 30 & & 80.42 \\
20 & 91.10 & 8.41 \\
10 & 1.53 & 2.48 \\
0 (free medical cost) & 2.30 & 1.24 \\
The Insured of Employees' Insurance & 5.17 & 7.45 \\
Whose Out-of-Pocket Costs Are Less Than 63,000 & & \\
\hline
\end{tabular}

Note: The law requires that insurers reimburse medical costs if individual out-of-pocket medical costs exceed 63,000 yen per month. Some insurers of Employees' Insurance reimburse out-of-pocket medical costs less than 63,000 yen. The table shows the percentage of the insured that are covered by such Employees' Insurance. 


\section{Table 2: Descriptive Statistics}

\begin{tabular}{lllll}
\hline & Mean & $\begin{array}{l}\text { Standard } \\
\text { deviation }\end{array}$ & Minimum & Maximum \\
\hline Medical service & .4177778 & .4942928 & 0 & 1 \\
Over-the-Counter medication & .4133333 & .4935296 & 0 & 1 \\
Do nothing & .1688889 & .3754891 & 0 & 1 \\
Age dummy (30s) & .2888889 & .4542568 & 0 & 1 \\
Age dummy (40s) & .2355556 & .4252917 & 0 & 1 \\
Age dummy (50s) & .2533333 & .4358899 & 0 & 1 \\
Female & .5955556 & .4918785 & 0 & 1 \\
College/University & .2444444 & .4307155 & 0 & 1 \\
Junior College & .1111111 & .3149704 & 0 & 1 \\
Technological College & .0533333 & .2246727 & 0 & 1 \\
Vocational School & .0933333 & .2915476 & 0 & 1 \\
Job Status & .7155556 & .4521553 & 0 & 1 \\
Labour income (in logs) & 3.283995 & 2.875901 & 0 & 7.467942 \\
Other income (in logs) & 5.156564 & 2.406581 & 0 & 8.243019 \\
Self-employed & .1644444 & .3715049 & 0 & 1 \\
Length of illness & 5.781499 & 6.606063 & 0 & 45 \\
Length of stay-in-bed & .3733333 & .9879633 & 0 & 10 \\
Temperature & 36.94533 & .7779253 & 36.5 & 42 \\
Frequency of catching cold & 3.564444 & 3.522451 & 0 & 25 \\
Regular exercise & .2666667 & .4432026 & 0 & 1 \\
Smoking & .2711111 & .4455245 & 0 & 1 \\
Drinking & .1022222 & .3036158 & 0 & 1 \\
Knowledge of Medications & .0355556 & .1855921 & 0 & 1 \\
OTC price (log) & 7.458036 & .0664637 & 7.316548 & 7.520235 \\
Coinsurance rate (\%) & 27.51303 & 11.18549 & 0 & 30 \\
\hline
\end{tabular}

Notes: (1) 'Medical service', 'Over-the-Counter Medication', and 'Do nothing' are dummy variables that take the value of 1 if a patient chooses the same, and 0 if otherwise.

(2) 'Female' is a dummy variable that takes the value of 1 if a patient is female, and 0 if male.

(3) 'Job status' is a dummy variable that takes the value of 1 if a patient works, and 0 if otherwise.

(4) 'Labour income' and 'Other income' are in units of 10,000 yen, in real 1995 values.

(5) 'Frequency of catching cold' is an average frequency of patients catching a cold within 
one year.

(6) 'Regular exercise' is a dummy variable that takes the value of 1 if patients exercise regularly at least once a week.

(7) 'Smoking' is a dummy variable that takes the value of 1 if patients smoke at least 10 cigarettes a day.

(8) 'Drinking' is a dummy variable that takes the value of 1 if patients drink heavily regularly or occasionally.

(9) 'Knowledge of medications' is a dummy variable that takes the value of 1 if patients know about $\mathrm{H}_{2}$ blocker, or if they answer that they have good knowledge of medications. 
Table 3: Cross tabulation between the Coinsurance Rate and

Treatment (Medical Services and Over-the-Counter Medication)

\begin{tabular}{|c|c|c|}
\hline Coinsurance Rate & Medical Services & $\begin{array}{l}\text { Over-the- } \\
\text { Counter } \\
\text { Medication }\end{array}$ \\
\hline $20 \%$ or less & .4423077 & .4326923 \\
\hline $30 \%$ & .4100719 & .4028777 \\
\hline \multicolumn{3}{|l|}{ In their $20 \mathrm{~s}$} \\
\hline $20 \%$ or less & .5217391 & .3913043 \\
\hline $30 \%$ & .3870968 & .3548387 \\
\hline \multicolumn{3}{|l|}{$30 \mathrm{~s}$} \\
\hline $20 \%$ or less & .4642857 & .4642857 \\
\hline $30 \%$ & .4761905 & .3809524 \\
\hline \multicolumn{3}{|l|}{$40 \mathrm{~s}$} \\
\hline $20 \%$ or less & .3846154 & .4615385 \\
\hline $30 \%$ & .4545455 & .4242424 \\
\hline \multicolumn{3}{|l|}{$50 \mathrm{~s}$} \\
\hline $20 \%$ or less & .4074074 & .4074074 \\
\hline $30 \%$ & .3030303 & .4545455 \\
\hline \multicolumn{3}{|l|}{ non worker } \\
\hline $20 \%$ or less & .5555556 & .3333333 \\
\hline $30 \%$ & .3454545 & .4181818 \\
\hline \multicolumn{3}{|l|}{ worker } \\
\hline $20 \%$ or less & .4315789 & .4421053 \\
\hline $30 \%$ & .452381 & .3928571 \\
\hline
\end{tabular}




\section{Table 4: Marginal Effect for Medical Services}

\begin{tabular}{llll}
\hline Explanatory variables & $\begin{array}{l}90 \% \text { confidence in- } \\
\text { terval lower bound }\end{array}$ & middle value & $\begin{array}{l}90 \% \text { confi- } \\
\text { dence interval } \\
\text { upper bound }\end{array}$ \\
\hline Age dummy (30s) & 0.075755 & 0.089754 & 0.10932 \\
Age dummy (40s) & 0.046432 & 0.061234 & 0.087907 \\
Age dummy (50s) & -0.075356 & -0.058565 & -0.035112 \\
Female & -0.056804 & -0.043996 & -0.032382 \\
College/University & -0.13538 & -0.12242 & -0.10965 \\
Junior or Technological College & -0.032373 & -0.020128 & 0.0071545 \\
Vocational School & 0.20522 & 0.21794 & 0.23847 \\
Job status & -0.030537 & -0.016102 & -0.0007071 \\
Labour income (in logs) & 0.020720 & 0.023427 & 0.025673 \\
Other income (in logs) & 0.026812 & 0.029387 & 0.031705 \\
Self-employed & -0.089425 & -0.075166 & -0.057010 \\
Length of illness & 0.0048693 & 0.0054312 & 0.0061722 \\
Length of stay-in-bed & 0.092646 & 0.097691 & 0.10639 \\
Temperature & 0.16952 & 0.17524 & 0.18363 \\
Frequency of catching cold & -0.0039203 & -0.0028118 & -0.0017499 \\
Regular exercise & 0.027009 & 0.036918 & 0.047897 \\
Smoking & -0.15247 & -0.13949 & -0.13066 \\
Drinking & 0.0031786 & 0.014187 & 0.027866 \\
Knowledge on medications & -0.12409 & -0.11619 & -0.10891 \\
OTC price (in logs) & -0.0011358 & 0.0016490 & 0.0042323 \\
Coinsurance rate (\%) & -0.30342 & -0.23134 & -0.16714 \\
\hline
\end{tabular}




\section{Table 5: Marginal Effect for Over-the-Counter Medication}

\begin{tabular}{llll}
\hline Explanatory variables & $\begin{array}{l}90 \% \text { confidence in- } \\
\text { terval lower bound }\end{array}$ & middle value & $\begin{array}{l}90 \% \text { confi- } \\
\text { dence interval } \\
\text { upper bound }\end{array}$ \\
\hline Age dummy (30s) & -0.038029 & -0.021656 & -0.0037727 \\
Age dummy (40s) & -0.047176 & -0.029114 & -0.010789 \\
Age dummy (50s) & 0.026683 & 0.044020 & 0.066014 \\
Female & -0.10701 & -0.092418 & -0.080440 \\
College/University & 0.14897 & 0.16070 & 0.17501 \\
Junior or Technological College & 0.12173 & 0.15670 & 0.17329 \\
Vocational School & -0.052486 & -0.040615 & -0.022406 \\
Job status & 0.0053742 & 0.018164 & 0.036388 \\
Labour income (in logs) & -0.017641 & -0.015308 & -0.012789 \\
Other income (in logs) & -0.021132 & -0.018506 & -0.016364 \\
Self-employed & 0.16273 & 0.18341 & 0.20038 \\
Length of Illness & -0.0021959 & -0.0014057 & -0.0007386 \\
Length of stay-in-bed & -0.11526 & -0.10347 & -0.097882 \\
Temperature & -0.072175 & -0.065083 & -0.058178 \\
Frequency of caching cold & 0.014542 & 0.016225 & 0.017512 \\
Regular exercise & 0.014710 & 0.025013 & 0.034571 \\
Smoking & 0.049912 & 0.059737 & 0.071234 \\
Drinking & -0.11239 & -0.10338 & -0.091596 \\
Knowledge on medications & 0.07580 & 0.094475 & 0.109611 \\
OTC prices (in logs) & -0.035053 & -0.031357 & -0.028619 \\
Coinsurance rate(\%) & 0.31817 & 0.39500 & 0.46690 \\
\hline
\end{tabular}

Note: Log likelihood is -303.88. An estimated coefficient and its 90\% C.I. (in parenthesis) of $\rho$ are $0.4902([0.25230 .7155])$ and of $\sigma$ are $1.080([0.62081 .4530])$. 


\section{Table 6: Marginal Effect for Medical Services (Estimation without OTC Prices)}

\begin{tabular}{llll}
\hline Explanatory variables & $\begin{array}{l}90 \% \text { confidence in- } \\
\text { terval lower bound }\end{array}$ & & $\begin{array}{l}90 \% \\
\text { confi- } \\
\text { dence interval } \\
\text { upper bound }\end{array}$ \\
\hline Age dummy (30s) & 0.094162 & 0.10904 & 0.12596 \\
Age dummy (40s) & 0.058447 & 0.073751 & 0.088186 \\
Age dummy (50s) & -0.087562 & -0.071816 & -0.059734 \\
Female & -0.040355 & -0.025080 & -0.012272 \\
College/University & -0.19360 & -0.17114 & -0.15825 \\
Junior College & -0.060434 & -0.036440 & -0.013853 \\
Technological College & 0.13954 & 0.16286 & 0.19362 \\
Vocational School & -0.07132 & -0.05194 & -0.04075 \\
Job status & -0.062499 & -0.046361 & -0.029385 \\
Labour income (in logs) & 0.026121 & 0.028619 & 0.031694 \\
Other income (in logs) & 0.022326 & 0.024903 & 0.027295 \\
Length of illness & 0.0050946 & 0.0056150 & 0.0063706 \\
Length of stay-in-bed & 0.10457 & 0.11061 & 0.11659 \\
Temperature & 0.14587 & 0.15295 & 0.16158 \\
Frequency of caching cold & 0.0012147 & 0.0020414 & 0.0030390 \\
Regular exercise & 0.019695 & 0.031323 & 0.041221 \\
Smoking & -0.10702 & -0.093575 & -0.081186 \\
Drinking & -0.0021399 & 0.010574 & 0.023818 \\
Knowledge of medications & -0.15934 & -0.16731 & -0.18247 \\
Coinsurance rate (\%) & -0.39609 & -0.36100 & -0.33693 \\
\hline
\end{tabular}




\section{Table 7: Marginal Effect for Over-the-Counter Medication (Estimation without OTC Prices)}

\begin{tabular}{llll}
\hline Explanatory variables & $\begin{array}{l}90 \% \text { confidence in- } \\
\text { terval lower bound }\end{array}$ & & $\begin{array}{l}\text { middle value } \\
\text { dence interval }\end{array}$ \\
& & & $\begin{array}{l}90 \\
\text { upper bound }\end{array}$ \\
\hline Age dummy (30s) & -0.032696 & -0.013255 & 0.0019483 \\
Age dummy (40s) & -0.047747 & -0.030063 & -0.014695 \\
Age dummy (50s) & 0.030228 & 0.044192 & 0.061157 \\
Female & -0.13174 & -0.11522 & -0.10036 \\
College/University & 0.27001 & 0.29228 & 0.30798 \\
Junior College & 0.22248 & 0.24986 & 0.28003 \\
Technological College & 0.064993 & 0.093516 & 0.11642 \\
Vocational School & -0.02309 & -0.02031 & -0.01778 \\
Job status & 0.015790 & 0.034538 & 0.053114 \\
Labour income (in logs) & -0.023096 & -0.020317 & -0.017778 \\
Other income (in logs) & -0.013986 & -0.0097153 & -0.0076227 \\
Length of illness & -0.0027371 & -0.0020713 & -0.0014113 \\
Length of stay-in-bed & -0.15209 & -0.14529 & -0.13928 \\
Temperature & -0.028401 & -0.021012 & -0.013803 \\
Frequency of catching cold & 0.014866 & 0.015636 & 0.016887 \\
Regular exercise & 0.0063930 & 0.016952 & 0.027654 \\
Smoking & -0.00026420 & 0.011449 & 0.025010 \\
Drinking & -0.13304 & -0.12418 & -0.10996 \\
Knowledge on medications & 0.12243 & 0.11076 & 0.098558 \\
Coinsurance rate (\%) & 0.272390 & 0.294820 & 0.33109 \\
\hline
\end{tabular}

Note: Log likelihood is -298.42. An estimated coefficient and its 90\% C.I. (in parenthesis) of $\rho$ are 0.4730 ([0.2038 0.7459]) and of $\sigma$ are 1.077 ([0.6823 1.5217]). 
Figure 1 Health Service Market

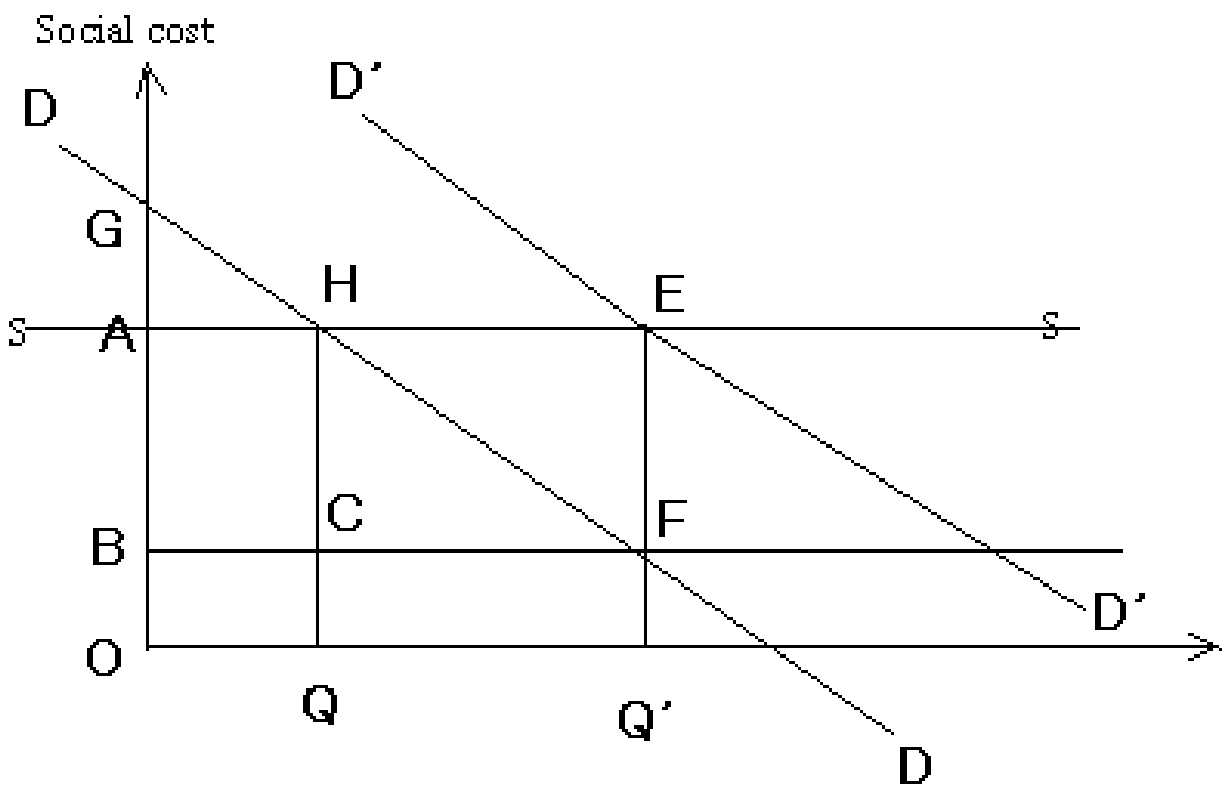

Ratio of patients who visited hospitals over the total patients 